\title{
Molecular cloning, expression of orange-spotted grouper goose-type lysozyme cDNA, and lytic activity of its recombinant protein
}

\author{
Zhi-Xin Yin ${ }^{1}$, Jian-Guo He ${ }^{1, *}$, Wei-Xin Deng ${ }^{1}$, Siu-Ming Chan ${ }^{2}$ \\ ${ }^{1}$ State Key Lab for Biocontrol, School of Life Sciences, Zhongshan University, 135 Xingang Road West, Guangzhou, 510275, \\ PR China \\ ${ }^{2}$ Department of Zoology, The University of Hong Kong, Pokfulam Road, Hong Kong SAR
}

\begin{abstract}
Lysozyme acts as a non-specific innate-immunity molecule against the invasion of bacteria pathogens. A leukocyte cDNA library of orange-spotted grouper Epinephelus coioides was constructed and the goose-type (g-type) lysozyme cDNA was isolated. The complete cDNA consists of an open reading frame of $585 \mathrm{bp}$ encoding a protein of 194 amino acids. This protein shows a $72.2 \%$ amino acid sequence identity with the flounder g-type lysozyme. Similar to most other species, the glu catalytic residue in g-type lysozymes of the grouper is conserved. Furthermore, like the flounder and carp, the 4 conserved cysteine residues identified in avian and mammalian g-type lysozymes were also absent from the grouper. Northern blot analysis indicated that the g-type lysozyme was expressed in intestine, liver, spleen, anterior kidney, posterior kidney, heart, gill, muscle and leukocytes. In addition, RT-PCR analysis detected the g-type lysozyme transcripts in the stomach, brain and ovary. When an orange-spotted grouper was injected with Vibrio alginolyticus, the number of lysozyme mRNA transcripts detected in the stomach, spleen, anterior kidney, posterior kidney, heart, brain and leucocytes increased $72 \mathrm{~h}$ after injection. Recombinant grouper g-type lysozyme produced in the Escherichia coli expression system showed lytic activity against Micrococcus lysodeikticus, V. alginolyticus from Epinephelus fario, V. vulnificus from culture water, Aeromonas hydrophila from soft-shell turtle, A. hydrophila from goldfish and $V$. parahaemolyticus, Pseudomonas fluorescens and V. fluvialis from culture water.
\end{abstract}

KEY WORDS: Goose-type lysozyme $\cdot$ Orange-spotted grouper $\cdot$ Lytic activity $\cdot$ cDNA library Resale or republication not permitted without written consent of the publisher

\section{INTRODUCTION}

Lysozyme (muramidase, EC.3.2.1.17) catalyzes the hydrolysis of the cell walls of most bacteria and results in a non-specific innate-immunity response against the invasion of bacterial pathogens (Jollès \& Jollès 1984). In vertebrates, there are 2 types of lysozyme: chickentype (c-type) and goose-type (g-type) (Jollès \& Jollès 1984). c-type lysozymes have been isolated from many vertebrates and insects (Prager \& Jollès 1996, Qasba \& Kumar 1997). In fishes, complete coding sequences of the c-type lysozymes of Japanese flounder (Hikima et al. 1997) (GenBank \#AB050469), turbot (GenBank \#AJ250732), rainbow trout (Dautigny et al. 1991) (GenBank \#X59491), zebra fish (GenBank \#AF402599) and common carp (GenBank \#AB027305) have been reported. G-type lysozymes have also been characterized in geese, chickens, black swans and ostriches (Canfield \& McMurry 1967, Simpson et al. 1980, Schoentgen et al. 1982, Nakano \& Graf 1991), and gtype lysozyme full-length cDNA sequences have been reported from chickens (Nakano \& Graf 1991), flounder (Hikima et al. 2001), carp (GenBank \#AB084624), mice (GenBank \#AK009014) and humans (GenBank \#BC029126). Despite this wealth of sequence information for $\mathrm{g}$-type lysozymes, expression studies have only been reported in chickens and flounder (Nakano \& Graf 1991, Hikima et al. 2001).

In fishes, lysozymes have a lytic effect on pathogenic bacteria. A g-type lysozyme from Japanese flounder showed lytic activity against Vibrio anguillarum (Hikima et al. 2001), and Lysozyme II from rainbow 
trout can kill $V$. anguillarum and $V$. salmonicida in Atlantic salmon, Aeromonas spp., A. salmonicida ssp. achromogenes, Yersinia ruckeri and Flavobacterium sp. in many fish species (Grinde 1989). These and other pathogenic bacteria could cause diseases in cultured fishes (Kusuda \& Salati 1993, Liao et al. 1996). The orange-spotted grouper Epinephelus coioides is an important cultured marine fish in southern China. Recently, bacteria that caused ulceration and high mortalities (50 to $70 \%$ ) in E. coioides cultures were reported in China (Liu et al. 1994, Zhu et al. 2000).

Expressed sequence tags (ESTs) are derived by partial, single-pass sequencing of the inserts from randomly selected cDNA clones. This approach has been used to identify many novel genes (Adams et al. 1991, 1993). In this study, we constructed a cDNA library from leukocytes of orange-spotted grouper for EST study and isolated a g-type lysozyme cDNA. Using Northern blot and RT-PCR analyses, we examined the expression of $g$-type lysozyme in different tissues. To study the function of the g-type lysozyme, we produced recombinant protein in bacteria and examined its lytic activity against Micrococcus lysodeikiticus and 7 strains of fish disease pathogens.

\section{MATERIALS AND METHODS}

Construction of leukocyte cDNA library. An orange-spotted grouper (602 g) was injected intramuscularly with Poly I:C (Amersham Pharmacia) at $1 \mathrm{mg}$ $\mathrm{kg}^{-1}$ body weight and peripheral blood was collected from the caudal artery $72 \mathrm{~h}$ after injection. Leukocytes were isolated from the blood sample using Ficollpaque plus (density $1.077 \mathrm{~g} \mathrm{ml}^{-1}$ ) (Amersham Pharmacia). Blood cell suspensions were layered over Ficollpaque plus, and centrifuged at $400 \times g$ for $30 \mathrm{~min}$ at room temperature. Cells recovered from the mediumFicoll interface were transferred to clean tubes, centrifuged at $200 \times g$ for $15 \mathrm{~min}$ at room temperature and washed twice with $0.9 \%$ sodium chloride.

Total RNA was isolated from leukocytes with Tripure reagents (Roche Diagnosis). The cDNA library was constructed using a SMART cDNA library construction kit (Clontech). Recombinant phages were packaged with Max Plax lambda packaging extract (Epicentre) and amplified in Escherichia coli XL1-Blue cells.

Molecular cloning of orange-spotted grouper g-type lysozyme cDNA. Individual phage plaques were isolated from plates and diluted in $0.5 \mathrm{ml}$ dilution buffer $(0.1 \mathrm{M}$ $\mathrm{NaCl}, 0.01 \mathrm{M} \mathrm{MgSO}_{4}, 0.035 \mathrm{M}$ Tris- $\mathrm{HCl} \mathrm{pH} 7.5,0.01 \%$ gelatin). The phage solution was used as a template for PCR amplification. TripIEx 5' and 3' long distance-insert screening amplimers (5':CTCGGGAAGCGCGCCATTGTGTTGGT, 3': ATACGACTCATATAGGGCGAA-
TTGGCC) were used as primers. After $10 \mathrm{~min}$ at $94^{\circ} \mathrm{C}$ for phage lysis, PCR was performed for 35 cycles at a denaturing temperature of $94^{\circ} \mathrm{C}$ for $30 \mathrm{~s}$, and at an annealing and extending temperature of $68^{\circ} \mathrm{C}$ for $3 \mathrm{~min}$. PCR products were analyzed on $1 \%$ agarose gel. DNA > 500 bp were purified with a DNA gel extraction kit (Sangon) and sequenced using an ABI PRISM Big Dye terminator kit on an ABI PRISM 377 sequencer. The sequences of inserts were compared with GenBank Database using the BLASTX program at www.ncbi. nlm.nih.gov/ BLAST/. The clone with the sequence most similar to the Japanese flounder g-type lysozyme was isolated.

Expression analysis by Northern blot and RT-PCR. For Northern blot analysis, 2 orange-spotted groupers were used: 1 fish (600 g) was injected intramuscularly with $2 \times 10^{5}$ cells of Vibrio alginolyticus and sacrificed for total RNA extraction (Tripure Reagents) after $72 \mathrm{~h}$. The other healthy fish (612 g) was also sacrificed for RNA extraction. For each fish, duplicate RNA samples $(25 \mu \mathrm{g})$ from different tissues were separated on 2 agarose gels $(1 \%)$ and transferred on 2 nitrocellulose membranes; 1 membrane was used for hybridization with a grouper $\mathrm{g}$ type lysozyme probe $\left(\left[\alpha-{ }^{32} \mathrm{P}\right]\right.$ deoxycytidine triphosphate) using a random primer DNA labeling kit (Takara). The other membrane was used for hybridization with a grouper $\beta$-actin probe. Hybridization was carried out in a hybridization buffer (1\% BSA, $7 \%$ sodium dodecyl sulfate $[\mathrm{SDS}] ; 0.5 \mathrm{M}$ phosphate-buffered saline, $\mathrm{pH} 6.8$; 1 mM EDTA, pH 8.0) at $68^{\circ} \mathrm{C}$ overnight. After hybridization, the membrane was washed in Buffer I $10.5 \%$ BSA; $5 \%$ SDS; $40 \mathrm{mM}$ phosphate buffer, $\mathrm{pH} 6.8 ; 1 \mathrm{mM}$ EDTA) at $68^{\circ} \mathrm{C}$ for $15 \mathrm{~min}$ and then in Buffer II (1\% BSA, $40 \mathrm{mM}$ phosphate buffer, $\mathrm{pH} 6.8 ; 1 \mathrm{mM}$ EDTA) at $68^{\circ} \mathrm{C}$ for $15 \mathrm{~min}$. The membranes were wrapped in plastic bags and exposed to X-ray film for $72 \mathrm{~h}$ with an intensifying screen at $-80^{\circ} \mathrm{C}$.

For RT-PCR analysis reverse transcription of RNA from different tissues of a healthy fish (625 g) was performed in a final concentration of $1 \times$ transcription buffer $(50 \mathrm{mM}$ Tris- $\mathrm{HCl}_{1} \mathrm{pH} 8.3 ; 75 \mathrm{mM} \mathrm{KCl} ; 3 \mathrm{mM} \mathrm{MgCl}_{2} ; 10 \mathrm{mM}$ dithiothreitol), $2.5 \mu \mathrm{M}$ random primers; and 1 Unit of Moloney murine leukemia virus reverse transcriptase (Promega). The reaction mixture $(20 \mu \mathrm{l})$ was incubated at $37^{\circ} \mathrm{C}$ for $1 \mathrm{~h}$. For PCR, a pair of primers containing the Bam HI and ECo RI restriction sites (Primer I: 5'-GCGGATCCATGGGTTATGGAAACAT-3'; Primer II: 5'CGGAATTCTTAGAAG CCTT-TCTGGG-3') were designed from the open reading frame of grouper $g$-type lysozyme cDNA. The final PCR mixture $(50 \mu \mathrm{l}$ per reaction) consisted of $10 \mathrm{mM}$ Tris- $\mathrm{HCl} \mathrm{pH} 8.5,1.5 \mathrm{mM} \mathrm{MgCl}_{2}$, $50 \mathrm{mM} \mathrm{KCl}, 10 \mathrm{pmol}$ of each primer, and an aliquot (1 $\mu \mathrm{l})$ of the reverse transcription product. The touch-down PCR included 30 cycles of $95^{\circ} \mathrm{C}$ for $30 \mathrm{~s}$, annealing at gradient temperatures of 60 to $45.5^{\circ} \mathrm{C}$ (each cycle $0.5^{\circ} \mathrm{C}$ 
lower than the former) for $30 \mathrm{~s}$ and extension at $72^{\circ} \mathrm{C}$ for $1 \mathrm{~min}$. An additional 20 cycles were performed: each at $94^{\circ} \mathrm{C}$ for $30 \mathrm{~s}$, at $45^{\circ} \mathrm{C}$ for $30 \mathrm{~s}$ and an extension at $72^{\circ} \mathrm{C}$ for $1 \mathrm{~min}$. At the end of the last cycle, the PCR mixture was incubated at $72^{\circ} \mathrm{C}$ for $10 \mathrm{~min}$ for the completion of DNA synthesis.

Construction of recombinant protein. The PCRamplified g-type lysozyme gene fragment was digested with BamHI and EcoRI, ligated into the pRSET A expression vector (Invitrogen) linearized with the same enzymes and transformed to XL1-Blue cells. After sequencing to ensure inframe insertion, the DNA construct was transformed to the host BL21 (DE3) pLysS strain for protein expression. The fusion protein was expressed by isopropyl-beta-D-thiogalactopyranoside (IPTG) induction, and SDS polyacrylamide gel (SDS-PAGE) electrophoresis was performed. To detect expression of recombinant fusion protein, Western blot was carried out using Ni-NTA AP conjugate (alkalinephosphatase conjugated nickel-nitrilotriacetic acid) (Qiagen). Recombinant bacteria $(1.5 \mathrm{ml})$ was collected, the pellet was resuspended in $500 \mu \mathrm{l}$ of phosphate buffer at neutral $\mathrm{pH}$, lysed in 3 consecutive freeze $\left(-80^{\circ} \mathrm{C}\right)$ and thaw (room temperature) cycles, and lysed by sonication on ice. The lysate was centrifuged at $10000 \times g$ for $10 \mathrm{~min}$ at $4^{\circ} \mathrm{C}$. The supernatant was freeze-dried and resuspended in $50 \mu \mathrm{l}$ of water, and used for lytic activity assays.

Lytic activity assays. The lytic activity assay used Micrococcus lysodeikticus as a substrate according to the method of Hikima et al. (2001). The M. lysodeikticus in $1 \%$ warm $\left(50^{\circ} \mathrm{C}\right)$ melting agarose $(50 \mathrm{mM}$ phosphate buffer, $\mathrm{pH}$ 6.2) was poured onto $80 \mathrm{~mm}$ plates. The concentration of $M$. lysodeikticus was adjusted to 0.2 absorbance units at $600 \mathrm{~nm}$ (about $10 \mathrm{mg} \mathrm{M}$. lyso-

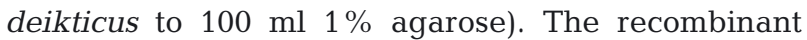
samples $(10 \mu l)$, the negative control samples and $250 \mu \mathrm{g}$ of hen egg-white lysozyme (Sigma) were put in individual wells in the agarose plates and incubated at $30^{\circ} \mathrm{C}$ for $24 \mathrm{~h}$. The diameters of the lysed circular zone were measured. Sonicated protein extracts from bacteria containing empty vectors were used for the controls.

To determine the lytic activity of the recombinant lysozyme against known fish disease pathogens, different bacteria (Vibrio alginolyticus from Epinephelus fario, $V$. vulnificus from the water in which the fish were cultured [culture water], Aeromonas hydrophila from soft-shell turtle, A. hydrophila from goldfish, $V$. parahaemolyticus, Pseudomonas fluorescens and $V$. fluvialis from culture water) were cultured overnight in Luria-Bertani medium and used as substrates in the lysoplate assay. For comparison, E. coli DH5 $\alpha$ and Micrococcus lysodeikticus were used as substrates in the assay.

\section{RESULTS}

\section{Nucleotide sequence of orange-spotted grouper g-type lysozyme cDNA}

The g-type lysozyme cDNA isolated from orange-spotted grouper was $788 \mathrm{bp}$ in length. The longest open reading frame consisted of $585 \mathrm{bp}$ and encoded a protein of 194 amino acid residues (Fig. 1). The cDNA consisted of a start codon (ATG), a stop codon (TAA) and a putative polyadenylation signal site (AATAAA) at $10 \mathrm{bp}$ upstream from the poly (A) tail. The calculated molecular mass of the g-type lysozyme was $21.18 \mathrm{kDa}$, with a PI (isoelectric point) of 5.93 using the Compute pI/MW program at www.us.expasy.org/tools/pi_tool.html. However, no signal peptide was found using the SignalP program at www.cbs.dtu.dk/services/SignalP-2.0 (Nielsen et al. 1997).

\section{Comparison of g-type lysozyme of orange-spotted grouper with those of other species}

Comparison of the deduced amino acid sequence of grouper g-type lysozyme with other known g-type lysozymes showed that the highest sequence identity was with that of Japanese flounder $(72.2 \%$ overall: Fig. 2). The next highest degree of sequence identity was with carp (50.3\%: Table 1). The Glu 71 catalytic residue in the grouper $g$-type lysozyme sequence was conserved as in other species listed in Table 1 except for the human sequence.

\section{Expression of g-type lysozyme in different tissues}

Northern blot analysis indicated that the g-type lysozyme was expressed in the intestine, liver, spleen, anterior kidney, posterior kidney, heart, gill, muscle and leukocytes, but not in the stomach, brain and ovary (Fig. 3). Using RT-PCR, the g-type lysozyme mRNA transcripts were detected in all tissues examined (Fig. 3). The additional detection of $\mathrm{g}$-type lysozyme expression in stomach, brain and ovary using the more sensitive RTPCR indicated low expression levels in these tissues. Furthermore, When an orange-spotted grouper was injected with Vibrio alginolyticus, the number of lysozyme mRNA transcripts detected in the stomach, spleen, anterior kidney, posterior kidney, heart, brain and leukocytes increased $72 \mathrm{~h}$ after injection (Fig. 3).

\section{SDS-PAGE and Western blot}

A $24.4 \mathrm{kDa}$ protein was detected in the recombinant bacteria but not in the negative control (Fig. 4). West- 


\begin{tabular}{|c|c|c|c|c|c|c|c|c|c|c|c|c|c|c|c|c|c|}
\hline 1 & $\mathrm{GC}$ & $C C$ & $\mathrm{GA}$ & $\mathrm{GA}$ & $\mathrm{AC}$ & $\mathrm{GA}$ & GG & $C A$ & TG & $\mathrm{CGT}$ & $B A C$ & CGT & $\mathrm{CT}$ & $\mathrm{CGT}$ & $\mathrm{ATT}$ & $\mathrm{CCG}$ & \\
\hline $\begin{array}{r}49 \\
1\end{array}$ & $\Gamma \mathrm{T}$ & CA & $\mathrm{G}$ & $A G A$ & CT & TTA & AA & GAG & A & $G$ & $\mathrm{TT}$ & A & $\begin{array}{l}\mathrm{TG} \\
\mathrm{M}\end{array}$ & GT & $\begin{array}{l}\text { CAT } \\
\mathrm{Y}\end{array}$ & $\begin{array}{c}\text { GGA } \\
\text { G }\end{array}$ & 6 \\
\hline 97 & $\mathrm{AC}$ & ATC & ATG & $\mathrm{AAT}$ & GTT & GAA & $\mathrm{ACT}$ & $\mathrm{ACT}$ & GGT & $\mathrm{GCA}$ & TCA & TGG & CAA & $\mathrm{ACG}$ & $\mathrm{GCT}$ & $\mathrm{CAG}$ & 144 \\
\hline & $\mathrm{N}$ & I & & 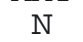 & V & $\mathrm{E}$ & $\mathrm{T}$ & & 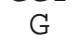 & 7. & 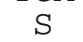 & & & $\mathrm{T}$ & A & - & 20 \\
\hline 45 & AG & $G A C$ & $A A G$ & $\mathrm{CTG}$ & GGA & TAC & TCA & GGT & GTG & AGG & $\mathrm{GCA}$ & TCA & $\mathrm{CAC}$ & $A C C$ & $\mathrm{ATG}$ & $\mathrm{GCA}$ & 192 \\
\hline & & $\mathrm{D}$ & 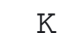 & 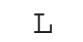 & G & $\mathrm{Y}$ & $S$ & & V & 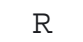 & 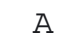 & $S$ & $\mathrm{H}$ & $\mathrm{T}$ & $M$ & A & \\
\hline & AÃC & $\mathrm{ACT}$ & GAC & TCA & GGC & AGA & ATG & GAG & AGG & TAC & AGG & ГСТ & $\mathrm{AA}$ & ATC & $\mathrm{AAC}$ & $\mathrm{TCC}$ & \\
\hline & N & 1 & D & $S$ & G & R & TH & 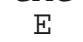 & $\mathrm{R}$ & $Y$ & $\mathrm{R}$ & 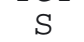 & $\mathrm{K}$ & $\mathrm{T}$ & 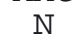 & $c$ & \\
\hline & GTG & GGA & $\mathrm{GCA}$ & $\mathrm{AAA}$ & TAC & GGA & $\mathrm{ATC}$ & GAT & $\mathrm{CCA}$ & $\mathrm{GCT}$ & $\mathrm{CTG}$ & ATT & $\mathrm{GCC}$ & $\mathrm{GCC}$ & $\mathrm{ATC}$ & $\mathrm{ATC}$ & \\
\hline & V & G & $\pi$ & K & $\mathrm{Y}$ & G & + & D & P & 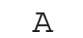 & 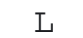 & 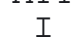 & $\pi$ & A & $2+$ & $2+$ & \\
\hline & TCC & GAA & GAG & TCC & AGG & $\mathrm{GCT}$ & GGA & $\mathrm{AAT}$ & GTA & TTA & CAT & GAT & GGC & TGG & GGA & GAC & \\
\hline & $\mathrm{S}$ & $\mathrm{E}$ & $E$ & $S$ & $\mathrm{R}$ & A & . & $\mathrm{N}$ & V & $\mathrm{L}$ & 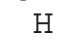 & D & G & W & $\mathrm{G}$ & 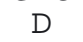 & \\
\hline 3 & TAT & GAC & TCA & AAC & AGA & GGA & GCG & TAC & AAC & $\mathrm{GCC}$ & TGG & GGA & CTG & ATG & $\mathrm{CAG}$ & GTT & \\
\hline & & 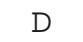 & $\mathrm{C}^{\prime}$ & ז & R & 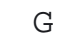 & 7 & Y & $\mathrm{N}$ & $\pi$ & & G & L & 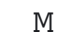 & $\mathrm{Q}$ & 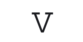 & \\
\hline & GAT & GTT & $\mathrm{AAT}$ & $\mathrm{CCA}$ & $\mathrm{AAT}$ & GGA & GGT & GGA & CAC & $\mathrm{ACT}$ & GCG & CGG & GGT & GCA & TGG & GAC & \\
\hline & & $\mathrm{V}$ & $\mathrm{N}$ & $\mathrm{P}$ & $\mathrm{N}$ & G & & & $\mathrm{H}$ & & & $\mathrm{R}$ & G & & & & \\
\hline & AGT & GAG & GAA & CAC & CTC & $\mathrm{TCT}$ & CAA & GGC & GCA & GAG & ATC & TTG & GTT & TAT & TTT & $\mathrm{ATT}$ & \\
\hline & S & 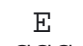 & 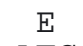 & $\mathrm{H}$ & L & S & Q & G & A & $E$ & $I$ & L & V & Y & $\mathrm{F}$ & I & \\
\hline & GGA & CGC & ATC & CGC & $A A C$ & AAG & TTT & $\mathrm{CCT}$ & GGC & TGG & $A A C$ & $\mathrm{ACG}$ & GAG & CAG & $\mathrm{CA}$ & CTG & \\
\hline & S & $D$ & I & 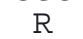 & $\mathrm{N}$ & K & $\square$ & $D$ & G & WT & ה & $\pi$ & ת & & & $T$ & \\
\hline & $\mathrm{AAA}$ & GGA & GGA & ATA & GCA & $\mathrm{GCC}$ & TAC & $\mathrm{AAT}$ & $\mathrm{ATG}$ & GGG & GAT & GGG & $\overline{A A C}$ & GTC & CÃC & $\mathrm{TCT}$ & \\
\hline & K & G & G & I & A & A & $\mathrm{Y}$ & $\mathrm{N}$ & M & $G$ & D & G & $\mathrm{N}$ & $\mathrm{V}$ & $\mathrm{H}$ & $\mathrm{s}$ & \\
\hline & TAT & GAT & $\mathrm{AAT}$ & GTG & GAT & GGC & $A G A$ & $A C A$ & $A C A$ & GGT & GGA & $\mathrm{GAC}$ & TAC & TCC & $\mathrm{AAT}$ & GAT & \\
\hline & Y & D & $1 \mathrm{v}$ & $\mathrm{V}$ & D & G & $\mathrm{R}$ & $\mathrm{T}$ & 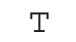 & 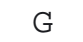 & & D & 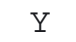 & 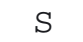 & 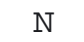 & 0 & \\
\hline & GTT & GTT & $\mathrm{GCC}$ & AGA & $\mathrm{GCT}$ & CAG & TGG & TAC & AAA & $A C C$ & CAG & AAA & GGC & TTC & TAA & $\mathrm{AAC}$ & \\
\hline & $\mathrm{V}$ & & & $R$ & 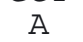 & & & & $\mathrm{K}$ & 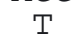 & & 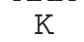 & ( & & & & \\
\hline & CTG & AAG & $\mathrm{CTC}$ & G & $\mathrm{TCA}$ & CAT & $\mathrm{CAG}$ & $\mathrm{AAA}$ & $\Gamma C A$ & $\operatorname{CTC}$ & TAA & $\mathrm{CTG}$ & TGC & $\mathrm{AT}$ & $T G$ & $\mathrm{TG}$ & \\
\hline & $\mathrm{TCT}$ & $G$ & TCA & $A A$ & $\mathrm{CCI}$ & TTC & CTA & A] & $\mathrm{A} z$ & A. & $\mathrm{AT}$ & $\mathrm{CC}$ & $\mathrm{AA}$ & $\mathrm{A} z$ & $A A$ & $\mathrm{~A}$ & \\
\hline & ת & & $\mathrm{AAA}$ & & $\mathrm{Az}$ & $\mathrm{AA}$ & & & & & & & & & & & \\
\hline
\end{tabular}

Fig. 1. Epinephelus coioides. Nucleotide sequence of orange-spotted grouper goose-type (g-type) lysozyme. Amino acid sequences represented by single capital letter below the respective nucleotide sequence; polyadenylation signal underlined

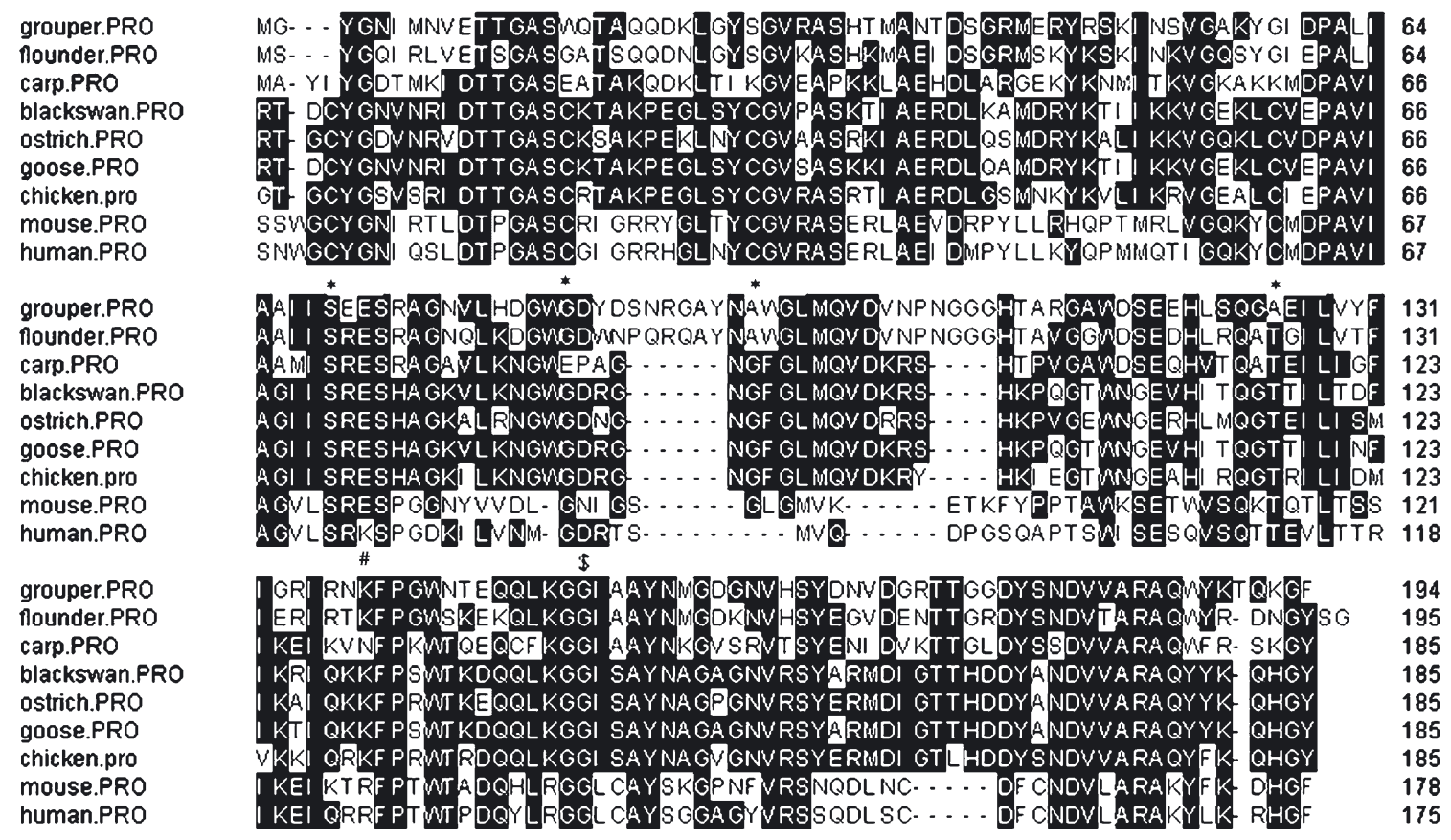

Fig. 2. Epinephelus coioides. Comparison of amino acid sequence of grouper g-type lysozyme with those of Japanese flounder, common carp, black swan, ostrich, goose, chicken, mouse and human. Under alignment of sequences, : cysteine residues of mouse, human, black swan, ostrich, goose and chicken sequences; \#: catalytic glu residue; and \$: conserved asp residue in grouper, flounder, human, black swan, ostrich, goose and chicken sequences 
Table 1. Identities of mature g-type lysozyme amino acid sequences in grouper Epinephelus coioides and other species

\begin{tabular}{|c|c|c|c|c|c|c|c|c|c|}
\hline Species & Grouper & Flounder & Carp & Black swan & Ostrich & Goose & Chicken & Mouse & Source/GenBank Ref. No. \\
\hline Flounder & 72.2 & & & & & & & & Hikima et al. (2001) \\
\hline Carp & 50.3 & 51.9 & & & & & & & \#AB084624 \\
\hline Black swan & 49.7 & 48.6 & 55.7 & & & & & & Simpson et al. (1980) \\
\hline Ostrich & 49.7 & 49.7 & 56.2 & 82.2 & & & & & Schoentgen et al. (1982) \\
\hline Goose & 48.6 & 48.6 & 56.8 & 96.8 & 83.8 & & & & Canfield \& McMurry (1967) \\
\hline Chicken & 47.0 & 48.1 & 54.6 & 81.1 & 77.8 & 80.5 & & & Nakano \& Graf (1991) \\
\hline Mouse & 31.5 & 31.5 & 35.4 & 40.4 & 41.0 & 39.9 & 39.9 & & \#AK009014 \\
\hline Human & 31.4 & 30.9 & 33.1 & 40.6 & 40.6 & 40.0 & 41.1 & 68.6 & \#BC029126 \\
\hline
\end{tabular}

ern blot analysis indicated that the $24.4 \mathrm{kDa}$ protein contained the $6 \times$ His tag sequence.

\section{Lysozyme activity}

The recombinant protein clearly caused lysis of $\mathrm{Mi}$ crococcus lysodeikticus at pH 6.2 and $30^{\circ} \mathrm{C}$ (Fig. 5). In

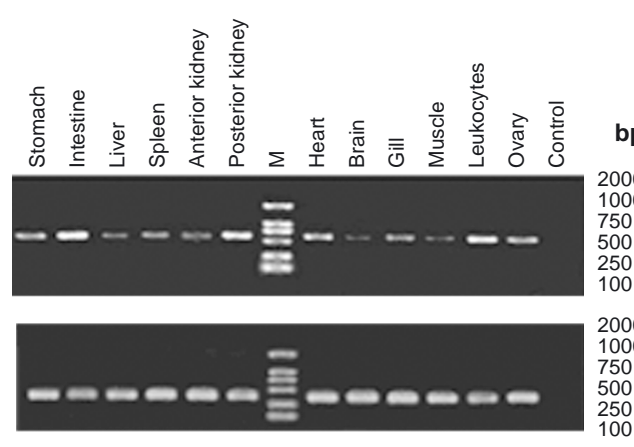

A
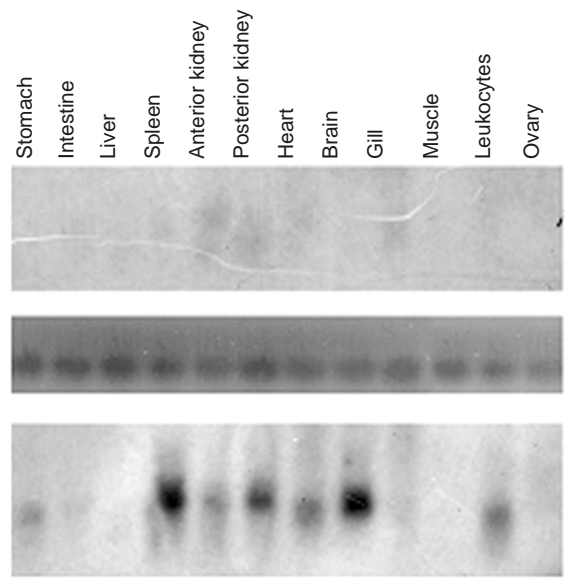

B

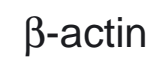

C

$\beta$-actin

Fig. 3. Expression of grouper g-type lysozyme in different tissues. (A) RT-PCR detection of lysozme in different tissues;

(B) Northern blot analysis of lysozyme in healthy fish;

(C) Northern blot analysis of lysozyme in fish infected with $2 \times$

$10^{5}$ cells of Vibrio alginolyticus. M: DL-2000 DNA ladder from Takara order to determine the lytic activity of the grouper $\mathrm{g}$ type lysozyme against fish disease pathogens, 7 bacteria strains (Vibrio alginolyticus from Ephinephelus fario, V. vulnificus from culture water, Aeromonas hydrophila from soft-shell turtle, A. hydrophila from goldfish and $V$. parahaemolyticus, Pseudomonas fluorescens and $V$. fluvialis from culture water) and Escherichia coli DH5 $\alpha$ were used as substrate. All the examined fish disease pathogens were lysed by the recombinant grouper g-type lysozyme (Fig. 6). However,

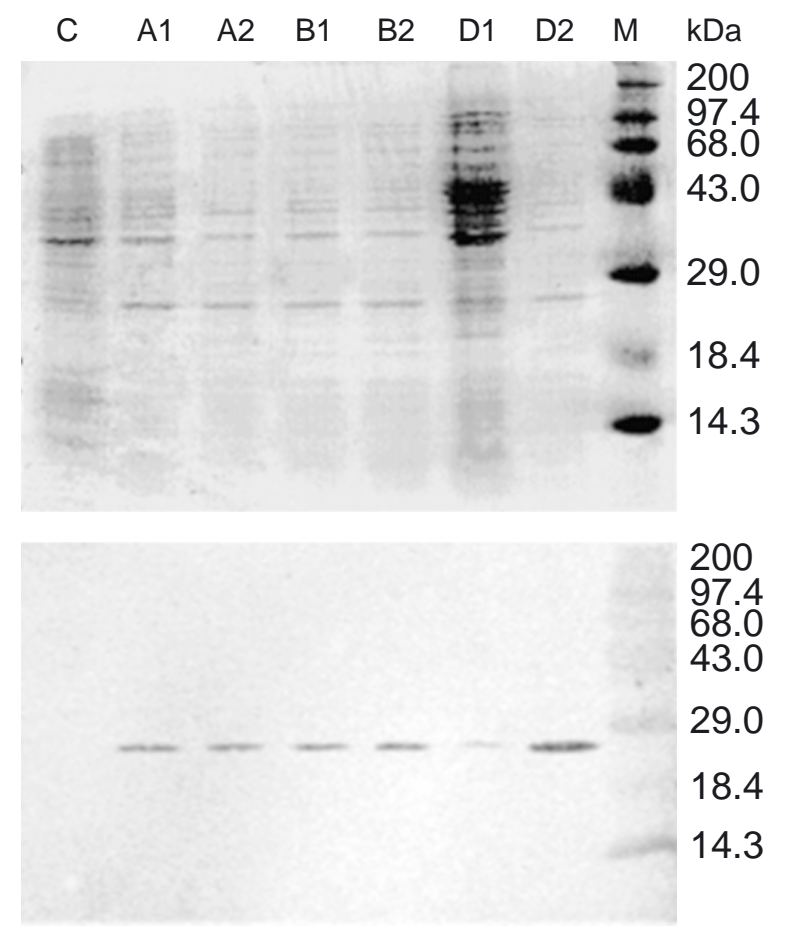

Fig. 4. Epinephelus coioides. Analysis of recombinant g-type lysozymes. (A) SDS-PAGE; (B) Western Blot. A1, B1, D1: total proteins of recombinant bacteria without isopropyl-beta-Dthiogalactopyranoside (IPTG) induction; A2, B2, D2: total proteins of recombinant bacteria with IPTG induction; C: total proteins of bacteria with empty plasmid pRSET A (Invitrogen) without IPTG induction. M: pre-stained protein molecular weight standards from Invitrogen 


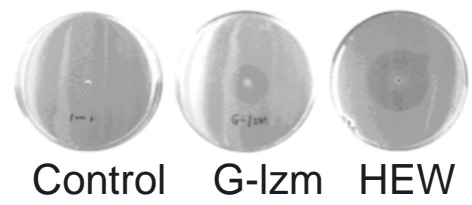

Fig. 5. Epinephelus coioides. Lytic activity of recombinant grouper g-type and hen egg-white c-type lysozyme against Micrococcus lysodeikticus. Small central circles are to same scale and represent the wells containing the samples; larger circles represent lysed halos formed by the lysozyme on $M$. lysodeikticus substrate. control: supernatant after sonication of the bacteria with empty pRSET A vector; G-lzm: supernatant after sonication of recombinant bacteria; HEW: hen egg-white lysozyme

the recombinant protein did not show a lytic effect on $E$. coli DH5 $\alpha$.

\section{DISCUSSION}

All the known avian g-type lysozymes contain 4 cysteine residues located in the $\mathrm{N}$-terminal half of the chain (Nakano \& Graf 1991). The recently reported putative g-type lysozymes of humans and mice contain the cysteine residues at the same location (GenBank \#BC029126, AK009014). Despite the fact that deduced g-type lysozymes of grouper and flounder lack these cysteine residues, recombinant g-type lysozyme from these fishes caused lysis of Micrococcus lysodeikticus (Hikima et al. 2001). This supports the hypothesis that disulfide bonding resulting from the cysteine residues is not necessary for lysozyme activity (Hikima et al. 2001). Additionally, the newly published g-type lysozyme from common carp also lacks cysteine residues (GenBank \#AB027305).

The chicken g-type lysozyme contains a signal peptide of 26 amino acid residues (Nakano \& Graf 1991). Using the SignalP program, a signal peptide of 19 amino acid residues can be identified in the human (GenBank \#BC029126) and mouse (GenBank \#AK009014) g-type lysozyme. However, the signal peptide sequence could not be detected from grouper g-type lysozyme. Using the carp g-type lysozyme sequence (GenBank \#AB027305), SignalP program was also unable to detect any signal peptide sequence. Hikima et al. (2001) obtained a similar result for flounder. This is a very interesting find, and further research is necessary to investigate this similarity between g-type lysozymes in grouper, flounder and carp.

It has been suggested that Glu 35 and Asp52 are important residues for lytic activity in c-type lysozymes, whereas Glu 73 and Asp 86 are the corresponding catalytic residues of avian g-type lysozymes (Prager \& Jollès 1996). The results from a higher resolution crystallographic study (Weaver et al. 1995) supported the equivalence of the Glu residues. However, Weaver et al. (1995) found no Asp 52 counterpart in gtype lysozyme and suggested that only 1 acidic residue is essential for the catalytic activity of g-type lysozyme and that Asp 52 might not be required for catalysis by the c-type lysozyme. The latter suggestion was supported by work in which an engineered chicken c-type lysozyme with Asn 52 had 5\% of wild-type activity (Malcolm et al. 1989). The Glu 71 and Asp 84 of grouper and flounder g-type lysozymes were conserved with Glu73 and Asp86 of avian g-type lysozymes (Fig. 2). However, the mouse and carp gtype lysozymes contain no Asp 84. If further studies are able to demonstrate that mouse and carp g-type lysozymes do cause lytic effects, this would support Weaver et al.'s suggestion.

The predicted molecular weight of the grouper gtype lysozyme $(21.18 \mathrm{kDa})$ is similar to that of Japanese flounder (22 kDa) (Hikima et al. 2001). Expression of the g-type lysozyme together with the $\mathrm{N}$-terminal tag appears to have resulted in an increase of approximately $3 \mathrm{kDa}$. As shown from SDS-PAGE and Western blot analyses, the recombinant protein has a molecular weight of $24.4 \mathrm{kDa}$, making its size close to the expected value.

In chickens, the g-type lysozyme is only expressed in the bone marrow and lung (Nakano \& Graf 1991). However, the Japanese flounder g-type lysozyme is expressed in the anterior kidney, posterior kidney, spleen, liver, skin, muscle, heart, brain, intestine, ovary and

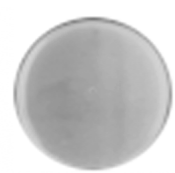

A

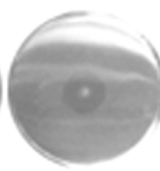

B

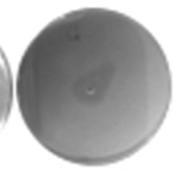

C

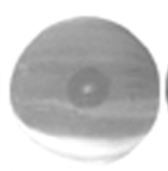

D

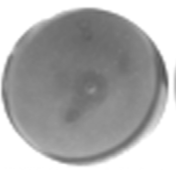

$\mathrm{E}$

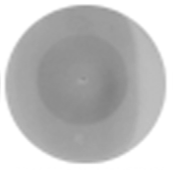

$\mathrm{F}$

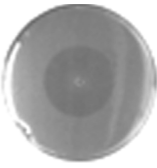

G

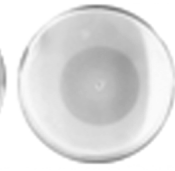

$\mathrm{H}$

Fig. 6. Epinephelus coioides. Lytic activity of recombinant grouper g-type lysozyme against 7 strains of fish disease pathogen and Escherichia coli DH5 $\alpha$. Small central circles are to same scale and represent the wells containing the samples; larger circles represent the lysed halos formed by lysozyme on bacteria substrate. (A) E. coli DH5 $\alpha_{\text {; }}$ (B) Vibrio alginolyticus from E. fario; (C) V. vulnificus from culture water; (D) Aeromonas hydrophila from soft-shell turtle; (E) A. hydrophila from gold fish; (F) V. parahaemolyticus from culture water; (G) Pseudomonas fluorescens from culture water; (H) V. fluvialis from culture water 
whole blood (Hikima et al. 2001). In orange-spotted grouper, RT-PCR analysis indicated that g-type lysozyme is also transcribed in these tissues, as well as in the stomach and gills. Thus, the pattern of expression of the lysozyme in orange-spotted grouper is similar to that in flounder but different from that in chickens.

Based on differences in cysteine content and expression profiles in different tissues, we suggest that fish gtype lysozymes may belong to a different subtype than that of the avian and mammalian $g$-type lysozymes.

Acknowledgements. We thank Dr. D. Rae for comments on the manuscript. This research was supported by Chinese National '863' Project under Grant No. 2001AA626030, Chinese National '973' Project under Grant No. G1999012010, and Guangdong Nature Science Foundation. We are also thankful to Mrs. S. P. Weng and Miss L. Z. Wang for their technical assistance.

\section{LITERATURE CITED}

Adams MD, Kelley JM, Gocayne JD, Dubnick M and 9 others (1991) Complementary DNA sequencing: expressed sequence tags and the human genome project. Science 252: $1651-1656$

Adams MD, Kerlavage AR, Fields C, Venter JC (1993) 3400 new expressed sequence tags identify diversity of transcripts in human brain. Nat Genet 4:256-267

Canfield RE, McMurry S (1967) Purification and characterization of a lysozyme from goose egg white. Biochem Biophys Res Commun 26:38-42

Dautigny A, Prager EM, Pham-Dinh D, Jolles J, Pakdel F, Grinde $B$, Jollès $P$ (1991) cDNA and amino acid sequences of rainbow trout (Oncorhynchus mykiss) lysozymes and their implications for the evolution of lysozyme and lactalbumin. J Mol Evol 32:187-198

Grinde B (1989) Lysozyme from rainbow trout, Salmo gairdneri Richardson, as an antibacterial agent against fish pathogens. J Fish Dis 12:95-104

Hikima J, Hirono I, Aoki T (1997) Characterization and expression of c-type lysozyme cDNA from Japanese flounder (Paralichthys olivaceus). Mol Mar Biol Biotechnol 6:339-344

Editorial responsibility: Donald Evans,

Athens, Georgia, USA
Hikima J, Minagawa S, Hirono I, Aoki T (2001) Molecular cloning, expression and evolution of the Japanese flounder goose-type lysozyme gene, and the lytic activity of its recombinant protein. Biochim Biophys Acta 1520:35-44

Jollès $\mathrm{P}$, Jollès J (1984) What's new in lysozyme research? Mol Cell Biochem 63:165-189

Kusuda R, Salati F (1993) Major bacterial diseases affecting mariculture in Japan. Annu Rev Fish Dis 3:69-85

Liao IC, Lee KK, Chien YH (1996) Practical approaches to marine fish health problems in Taiwan. In: Main KL, Rosenfeld C (ed) Aquaculture health management strategies for marine fish in Asia and the United States. The Oceanic Institute, Honolulu, p 57-67

Liu X, Zou X, Mo X (1994) A study on the pathogen of vibrisis isolated from diseased Epinephelus sp. in cage mariculture. Trop Oceanol 13:81-86

Malcolm BA, Rosenberg S, Corey MJ, Allen JS, de Baetselier A, Kirsch JF (1989) Site-directed mutagenesis of the catalytic residues Asp-52 and Glu-35 of chicken egg white lysozyme. Proc Natl Acad Sci USA 86:133-137

Nakano T, Graf T (1991) Goose-type lysozyme gene of the chicken: sequence, genomic organization and expression reveals major differences to chicken-type lysozyme gene. Biochim Biophys Acta 1090:273-276

Nielsen H, Engelbrecht J, Brunak S, Heijne G (1997) Identification of prokaryotic and eukaryotic signal peptides and prediction of their cleavage sites. Protein Eng 10:1-6

Prager EM, Jollès P (1996) Animal lysozymes C and g: an overview. In: Jollès $\mathrm{P}$ (ed) Lysozymes: model enzymes in biochemistry and biology. Birkhäuser Verlag, Basel, p 9-31

Qasba PK, Kumar S (1997) Molecular divergence of lysozyme and alpha-lactalbumin. Crit Rev Biochem Mol Biol 32: 255-306

Schoentgen F, Jollès J, Jollès P (1982) Complete amino acid sequence of ostrich (Struthio camolus) egg white lysozyme, a goose-type lysozyme. Eur J Biochem 123:489-497

Simpson R.J, Begg GS, Dorow DS, Morgan FJ (1980) Complete amino acid sequence of the goose-type lysozyme from the egg white of the black swan. Biochemistry 19: $1814-1819$

Weaver LH, Grutter MG, Matthews BW (1995) The refined structure of goose lysozyme and its complex with a bound trisaccharide show that the 'goose-type' lysozymes lack a catalytic aspartate residue. J Mol Biol 245:54-68

Zhu C, He J, Huang Z (2000) Identification and pathogenicity of pathogen of Epinephalus fario and E. awoara ulceration disease, Acta Sci Nat Univ Sunyatseni 39(Suppl):278-281

Submitted: June 16, 2002; Accepted: January 7, 2003

Proofs received from author(s): June 24, 2003 